\title{
Peran penyuluh dalam meningkatkan adopsi inovasi teknologi pakan ternak sapi di Kecamatan Totikum Kabupaten Banggai Kepulauan
}

\author{
A. I. Z. Radjab, J Lainawa*, G. D. Lenzun \\ Fakultas Peternakan Universitas Sam Ratulangi Manado 95115 \\ *Korespondensi (corresponding author) : jlainawa@gmail.com
}

\begin{abstract}
ABSTRAK
Tujuan Penelitian ini adalah untuk mengetahui peranan penyuluhan terhadap proses adopsi inovasi penggunaan teknologi pakan dalam meningkatkan populasi ternak sapi potong. Penentuan responden pada penelitian kualitatif ini dilakukan secara "pusposive sampling" terhadap 22 peternak sebagai responden berdasarkan kriteria memiliki ternak sapi potong diatas 3 ekor dengan pengalaman diatas 3 tahun. Hasil penelitian menunjukkan bahwa penyuluhan terhadap responden tdak pada materi khusus tentang teknologi pakan, meskipun petani sangat membutuhkan pengetahaun itu untuk pengembangan usaha pemeliharaan ternak. Selain itu persepsi petani menyatakan bahwa penyuluh yang ada tidak dalam kompetensi ahli dibidang peternakan akibat latar belakang pendidikan formalnya bukan dibidang peternakan. Secara umum usaha peternakan sapi potong di Kecamatan Totikum Kabupaten Banggai Kepulauan masih bertujuan untuk memenuhi kebutuhan pangan keluarga bukan untuk komersial, namun jika dalam keadaan mendesak petani menjual ternak sapi melalui pedagang perantara yang ada didesa dengan harga yang kurang menguntungkan petani. Dengan demikian disimpulkan kegiatan penyuluhan yang dilakukan di Kecamatan Totikum Kabupaten Banggai Kepulauan tidak berperan dalam proses adopsi inovasi teknologi pakan ternak sapi potong.
\end{abstract}

Kata kunci : Peranan Penyuluhan, Adopsi Inovasi, Teknologi Pakan, Ternak Sapi Potong.

\begin{abstract}
THE ROLE OF COUNSELING IN INSCREASING ADOPTION INOVATION OF FEED TECHNOLOGY ON BEEF CATTLE IN DISTRICT OF TOTIKUM BANGGAI ISLANDS. The aim of this study was to determine the role of guidance in introducing innovations in the use of feed technology in increasing the cattle population. The respondents in this qualitative study were determined by means of "targeted sampling", with 22 breeders being selected as respondents, based on the criteria of having more than 3 cattle with experience over 3 years. The results showed that the advice given to respondents did not relate to specific feed technology material, although farmers really need this knowledge for the development of livestock businesses. In addition, the perception of farmers is that due to their formal educational background, the existing cultivation workers fall under the competence of animal husbandry experts and were not in the animal husbandry field. In general, cattle farming in Totikum Subdistrict, Banggai Islands Regency was still aimed at meeting family food needs, not for commercial purposes, but when in an emergency situation farmers sell cattle through
\end{abstract}


intermediaries in the village at a price that was not affordable for farmers. Therefore, it was concluded that the expansion activities carried out in Totikum District, Banggai Islands Regency played no role in the introduction of innovations in cattle feed technology.

Keywords: role of expansion, introduction of innovations, feed technology, cattle.

\section{PENDAHULUAN}

Peningkatan produksi ternak sapi potong sangat tergantung dari tiga faktor utama yaitu pakan, pemuliabiakan (reproduksi) dan system pemeliharaan. Pakan bagi ternak ruminansia tergantung dari penyediaan hijauan dengan jumlah cukup, berkualitas tinggi dan berkesinambungan sepanjang tahun. Karena itu diperlukan adopsi inovasi teknologi melalui penyuluhan untuk untuk pemberdayaan petani (Rusdiana dan Praharani, 2018).

Penyuluhan pertanian, perikanan, dan kehutanan merupakan proses pembelajaran bagi pelaku utama agar mereka mau dan mampu menolong dan mengorganisasikan dirinya dalam mengakses informasi pasar, teknologi, permodalan, dan sumber daya lainnya, sebagai upaya untuk meningkatkan produktivitas, efisiensi usaha, pendapatan, dan kesejahteraannya, serta meningkatkan kesadaran dalam pelestarian fungsi lingkungan hidup (Umar et al., 2021).

Peran penyuluh pertanian sangat menentukan keberhasilan pembangunan teknologi pakan ternak sapi potong. Penyuluh pertanian adalah orang yang mengemban tugas memberikan dorongan kepada petani agar mau mengubah cara befikir, cara kerja dan cara hidup yang lebih sesuai dengan perkembangan teknologi pertanian yang lebih maju (Narso et al., 2012).

Peran penyuluh pertanian dapat dikatakan sebagai garda terdepan untuk meningkatkan kualitas petani. Penyuluh berperan sebagai perantara dan penghubung informasi untuk petani, dimana penyuluh melakukan penyampaianan informasi kepada petani serta jika memungkinkan dapat menyampaikan aspirasi dari petani ke pembuat kebijakan (Sundari et al., 2015).

$$
\text { Proses adopsi merupakan }
$$

serangkaian kegiatan dalam memutuskan menerima atau menolak suatu inovasi selama periode waktu tertentu. Proses pengambilan keputusan inovasi merupakan suatu aktivitas individu/organisasi yang terjadi secara bertahap. Yafi (2017) mengungkapkan teori keputusan dalam adopsi inovasi yaitu adopsi inovasi merupakan suatu proses penerimaan atau penerapan inovasi oleh individu.

Persyaratan utama agar inovasi dapat diterima dengan baik oleh penerima manfaat sebagai berikut (Mardikanto, 2010; Sumardjo et al., 2015). (1) Kesesuaian dengan kebutuhan pengguna Inovasi harus dikembangkan dengan mengacu pada kebutuhan masyarakatdan disampaikan pada saat sedang dibutuhkan atau menjelang sesuatu yang baru tersebut dibutuhkannya. (2) Kemudahan dipahami oleh pengguna inovasi harus disampaikan dengan bahasa atau komunikasi yang mudah dipahami oleh pengguna. (3) Keterjangkauan biaya inovasi harus dikembangkan dengan mempertimbangkan kemampuan pengguna dalam pembiayaan atau menyediakan korbanan untuk perubahan. (4) Daya tarik manfaatInovasi harus dapat dipahami bahwa manfaatnya akan memenuhi harapan penggunanya. (5) Kesesuaian dengan situasi dan kondisi setempatInovasi harus merupakan sesuatu yang dapat diterapkan sesuai dengan kondisi, baik 
tingkat pengetahuan, keterampilan, maupun sumberdaya, yang dapat diakses pihak yang diharapkan menjadi penggunanya.

Pakan yang baik akan menjadikan ternak sanggup menjalankan fungsi proses dalam tubuh secara normal. Secara umum untuk pengembangan pakan memiliki permasalahan, menurut Abdullah dan Ibrahim (2014), disebabkan antara lain; (a) kebutuhan bahan baku pakan tidak seluruhnya dipenuhi dari lokal sehingga masih mengandalkan impor, (b) bahan baku pakan lokal belum dimanfaatkan secara optimal, (c) ketersediaan pakan lokal tidak kontinyu dan kurang berkualitas, (d) penggunaan tanaman legum sebagai sumber pakan belum optimal, (e) pemanfaatan lahan tidur dan lahan integrasi masih rendah, (f) penerapan teknologi pakan masih rendah, g) produksi pakan nasional tidak pasti akibat akurasi data yang kurang tepat, serta (h) penelitian dan aplikasinya tidak sejalan.

Kesediaan dan harga jenis pakan sangat tergantung pada musim, jika musim kemarau atau musim hujan terlalu panjang, maka para peternak akan kesulitan mencari bahan pakan untuk ternaknya dan harga rumput sangat tinggi pada musim kemarau karena kelangkaannya, sedangkan pada musim penghujan ketersediaanya sangat melimpah dan harganya murah (Sari, 2017).

Menurut Laut et al. (2018), pemanfaatan teknologi dalam dunia peternakan belum banyak dirasakan oleh sebagian petani ternak, karena teknologi yang ada sekarang memerlukan biaya yang tinggi dan kurang cocok bila diterapkan pada petani ternak karena keterbatasan sarana dan prasarana serta sumber daya manusia yang kurang mendukung. Padahal teknologi dalam dunia peternakan sangat diperlukan dalam rangka peningkatan produksi dan peningkatan kualitas produk yang dihasilkan. Adawiyah (2017), menyatakan bahwa adopsi dapat diartikan sebagai proses perubahan perilaku baik yang berupa pengetahuan (cognitive), sikap (affective), maupun ketrampilan (psychomotoric) pada diri seseorang setelah menerima inovasi yang disampaikan. Masyarakat harus yakin bahwa inovasi itu memenuhi suatu kebutuhan yang benarbenar dirasakan (Rusdiana, 2014). Dilain pihak, Syatra (2016), menyatakan bahwa berhasil tidaknya pengembangan teknologi ditentukan oleh mau tidaknya petani menerapkan teknologi yang di anjurkan.

Di Kabupaten Banggai Kepulauan, Peternakan sapi potong sudah di kembangkan secara turun temurun dengan sistim tradisional yaitu sistim pemeliharaan dengan cara melepas ternak di ladang perkebunan mereka. Sapi potong yang dipelihara petani diberikan makanan hijauan dan konsentrat. Namun kebanyakan hanya diberikan hijauan dan limbah pertanian secara alamiah, belum menggunakan metode teknologi pakan. Sehingga dibutuhkan upaya adopsi inovasi terhadap teknologi pakan. Hipotesis yang digunakan dalam penelitian ini adalah apakah kegiatan berperan atau tidak berperan terhadap proses adobsi inovasi teknologi pakan ternak sapi potong di Kecamatan Totikum Kabupaten Banggai Kepulauan.

Akibatnya perkembangan populasi ternak terjadi sangat lambat. Populasi sapi potong di Kabupaten Banggai Kepulauan dibeberapa tahun terakhir ini mulai menurun (BPS Banggai Kepulauan 2018). Dari data populasi ini sudah terlihat bahwa perlu adanya peningkatan produksi ternak sapi potong didaerah ini dengan meningkatkan kualitas pakan yang dulunya hanya menggunakan pakan lokal atau tradisional, peternak harus memiliki pemahaman yang lebih dalam dengan adanya kegiatan penyuluhan tentang adopsi teknologi pakan. Dalam pengembangan usaha ternak sapi potong, petani didaerah Kecamatan Totikum Kabupaten Banggai Kepulauan hanya 
menggunakan bahan pakan tradisional seperti kulit pisang, batang pisang, rumput liar yang tumbuh didaerah perkebunan mereka. Hal ini diduga yang menjadi faktor penyebab perkembangan produksi lambat. Oleh sebab itu maka perlu dilakukan upaya adopsi teknologi pakan melalui kegiatan penyuluhan.

\section{METODE PENELITIAN}

\section{Lokasi \& waktu penelitian}

Penelitian ini dilaksanakan pada Kecamatan Totikum Kabupaten Banggai Kepulauan Provinsi Sulawesi Tengah. mulai bulan Februari sampai dengan Bulan Maret 2018.

\section{Populasi, sampel dan teknik sampling} Penentuan sampel peternak sebagai responden dari populasi peternak ditentukan dengan metode "pusposive sampling" dimana dipilih peternak sapi potong yang memiliki ternak sapi potong diatas 3 ekor dengan pengalaman memelihara ternak diatas 3 tahun serta pernah mengikuti penyuluhan peternakan sapi potong. Sebanyak 35 petani di Kecamatan Totikum Kabupaten Banggai Kepulauan yang memelihara ternak sapi potong local (peranakan ongole-PO), namun yang memenuhi kriteria untuk dijadikan responden adalah sebanyak 22 petani.

\section{Instrumen penelitian}

Instrumen penelitian yang dipergunakan dalam proses pengumpulan data adalah kesiapan peneliti sendiri dengan bantuan penelitian seperti alat perekam suara, alat rekam visual, alat tulis, laptop untuk menyimpan data hasil penelitian serta fasilitas internet.

Pengumpulan data penelitian dilakukan dengan survey menggunakan kuesioner. Data yang diperoleh tersebut akan berbentuk angka-angka, tabel-tabel, analisa statistik dan uraian serta kesimpulan penelitian. Kuesioner bersifat efisien sehingga cocok digunakan bila jumlah responden cukup besar dan tersebar diwilayah yang luas. Penelitian ini menggunakan metode deskriptif dengan fokus analisis pada data angka (numerical) untuk mengukur respon para respsponden terhadap kegiatan penyuluhan yang dilakukan kepada petani. Sondakh et al., (2019), metode deskriptif, yaitu suatu metode atau cara menganalisis dan menguraikan data penelitian yang ada, dan dikaitkan dengan teori-teori yang ada.

\section{Pengolahan dan analisis data.}

Penelitian ini menggunakan proses analisis empat tahap kualitatif yaitu mengumpulkan data, mereduksi data, menyajikan data dan menyimpulkan. Analisis data kualitatif menurut Moleong (2017), adalah upaya yang dilakukan dengan jalan bekerja dengan data, mengorganisasikan data, memilah-milahnya menjadi satuan yang dapat dikelola, mengsintesiskannya, mencari dan menemukan pola, menemukan apa yang penting dan apa yang dipelajari, dan memutuskan apa yang akan diceritakan kepada orang lain.

Menurut Sugiyono (2017), aktivitas dalam analisis data kualitatif yaitu data reduction, data display serta conclusion drawing.

\section{Variabel penelitian dan pengukurannya}

1. Potensi Wilayah : Kemampuan sumberdaya wilayah dalam hal mendukung pengembangan usaha ternak sapi potong.

2. Potensi Ternak Sapi Potong : Perkembangan populasi ternak sapi

3. Potensi Hijauan Makanan Ternak; Kemampuan daya dukung hijauan untuk pakan ternak sapi potong 
4. Intensitas penyuluhan peternakan sapi : jumlah kegiatan penyuluhan peternakan yang dilakukan penyuluh

5. Persepsi petani : adalah tanggapan petani terhadap penyuluhan teknologi pakan ternak yang diukur dengan jawaban ; sangat suka, suka, ragu-ragu, tidak suka dan sangat tidak suka.

\section{HASIL DAN PEMBAHASAN}

\section{Deskripsi potensi wilayah}

Kabupaten Banggai Kepulauan yang terletak di perairan sebelah timur Sulawesi Tengah ini merupakan kabupaten baru hasil pemekaran dari Kabupaten Banggai pada tahun 1999 berdasarkan UU No. 51/1999. Selanjutnya pada tahun 2013 di wilayah Kabupaten Banggai Kepulauan kembali terjadi pemekaran Daerah Otonomi Baru (DOB) yaitu Kabupaten Banggai. Laut sesuai dengan UU No. 5 Tahun 2013.

Kabupaten Banggai Kepulauan memiliki luas wilayah daratan $2.488,79 \mathrm{~km} 2$ dan luas wilayah lautnya $\pm 6.671,32 \mathrm{~km} 2$ dan terdiri atas 235 gugusan pulau-pulau, pulau berpenghuni sebanyak dua pulau yaitu

Pulau Peling dan Pulau Bakalan, dan tidak berpenghuni 233 pulau. Kabupaten Banggai Kepulauan terbagi dalam 12 Kecamatan, dengan ibukota Kabupaten di Kota Salakan,

tepatnya di Pulau Peling. Untuk jelasnya mengenai kondisi administrasi di Kabupaten Banggai Kepulauan, dapat dilihat pada tabel 1 .

Secara geografis, Kabupaten Banggai Kepulauan terletak diantara antara $1^{\circ} 06 " 30 "$ Lintang Selatan sampai dengan $1^{\circ} 35^{\prime} 58^{\prime \prime}$ Lintang Selatan dan $122^{\circ} 37^{\prime} 6,3^{\prime \prime}$ Bujur Timur sampai dengan $123^{\circ} 40^{\prime} 1,9^{\prime \prime}$ Bujur Timur di Jazirah Timur Laut Pulau Sulawesi, dengan batasan sebagai berikut :

- Sebelah Utara berbatasan dengan Kabupaten Banggai, Sebelah Selatan berbatasan dengan Kabupaten Banggai Laut, Sebelah Timur berbatasan Laut Maluku, Sebelah Barat berbatasan dengan Selat Peling. Untuk saat ini sektor pertanian merupakan potensi utama di Kabupaten banggai kepulauan terutama kegiatan

Tabel 1. Luas Wilayah Per Kecamatan Kabupaten Banggai Kepulauan, 2018

\begin{tabular}{clrrrr}
\hline \multirow{2}{*}{ No } & \multirow{2}{*}{ Kecamatan } & \multicolumn{2}{c}{ Luas Wilayah } & & \\
\cline { 3 - 6 } & & Darat & $\%$ & Laut & $\%$ \\
\hline 1 & Totikum & 155,45 & 12,55 & $1.082,85$ & 87,45 \\
2 & Totikum Selatan & 95,19 & 12,55 & 663,09 & 87,45 \\
3 & Tinangkung & 312,60 & 41,16 & 446,96 & 58,84 \\
4 & Tinangkung Selatan & 187,89 & 42,79 & 251,23 & 57,21 \\
5 & Tinangkung Utara & 136,65 & 41,16 & 195,38 & 58,84 \\
6 & Liang & 176,19 & 25,76 & 507,78 & 74,24 \\
7 & Peling Tengah & 140,00 & 25,76 & 403,49 & 74,24 \\
8 & Bulagi & 275,66 & 47,59 & 303,58 & 52,41 \\
9 & Bulagi Selatan & 319,00 & 47,58 & 351,45 & 52,42 \\
10 & Bulagi Utara & 318,00 & 47,59 & 350,21 & 52,41 \\
11 & Buko & 184,84 & 14,96 & $1.050,60$ & 85,04 \\
12 & Buko Selatan & 187,32 & 14,96 & $1.064,70$ & 85,04 \\
Total & 2.488,79 & 27,17 & $6.671,32$ & 72,83 & \\
\hline
\end{tabular}


pertanian. Kabupaten Banggai kepulauan Kepulauan memiliki luas lahan persawahan yang telah terolah $596 \mathrm{Ha}$ dengan produksi rata-rata 3,37 ton perhektar. Selain itu, produksi yang paling menonjol adalah kelapa dalam.

Produksi kelapa dalam mencapai 2.252 ton dari total lahan $27.070 \mathrm{Ha}$. Bangkep juga merupakan salah satu daerah penghasil jambu mente di Sulawesi Tengah. Luas lahan perkebunan jambu mente mencapai 10.825 Ha dengan jumlah produksi 2.061 ton. Selain ketiga komoditi tersebut bangkep juga menghasilkan kopi, cengkih, vanili, kakao, kemiri, lada dan pala. Komoditi lainnya adalah pisang dengan produksi 1.230 ton yang diekspor dan diantarpulaukan, durian 314 ton pertahun, mangga 362,5 ton dan nangka 693 ton pertahun.

\section{Deskripsi potensi ternak sapi potong}

Kecamatan Totikum memiliki populasi ternak sapi potong terbanyak di bandingkan kecamatan lainnya di kabupaten Banggai kepulauan. Tabel 2, berdasarkan data yang diperoleh dari hasil penelitian, populasi sapi potong pada tahun 2018 adalah 3.884 ekor (BPS Banggai 2018).

Tabel 2. Jumlah Populasi Ternak

\section{Deskripsi keadaan usaha peternakan Sapi potong di Kecamatan Totikum}

Pola usaha peternakan sapi potong di Kecamatan Totikum Kabupaten Banggai Kepulauan kebanyakan masih dilakukan dengan cara tradisional. Ternak sapi hanya digembalakan secara liar pada lahan-lahan pertanian dan perkebunan yang ada disekitar tempat tinggal petani. Para petani masih mengandalkan sistem pemeliharaan induk anak (pembibitan) sebagai penyedia bakalan (cow calf operation). Program CCO (cow calf operation) merupakan usaha untuk menghasilkan pedet atau sapi bakalan (Malotes, 2016). Secara umum usaha peternakan sapi potong di Kecamatan Totikum Kabupaten Banggai Kepulauan masih bertujuan untuk memenuhi kebutuhan pangan keluarga bukan untuk komersial, namun jika dalam keadaan mendesak petani menjual ternak sapi melalui pedagang perantara yang ada didesa dengan harga yang kurang menguntungkan petani. Beberapa upaya telah dilakukan oleh pemerintah setempat dalam meningkatkan populasi dengan memberikan bantuan bibit/induk ternak sapi bali dan bantuan bibit unggul sekaligus fasilitasi melalui teknologi inseminasi buatan (IB), namun sampai saat ini usaha tersebut belum belum dapat mememnuhi kesejahtraan

\begin{tabular}{clc}
\hline No & \multicolumn{1}{c}{ Kecamatan } & Jumlah Populasi Ternak Sapi Potong (Ekor) \\
\hline 1 & Totikum & 3884 \\
2 & Totikum Selatan & 924 \\
3 & Tinangkung & 2197 \\
4 & Tinangkung selatan & 2158 \\
5 & Tinangkung Utara & 2511 \\
6 & Liang & 69 \\
7 & Peling Tengah & 1097 \\
8 & Bulagi & 1088 \\
9 & Bulagi Selatan & 3245 \\
10 & Bulagi Utara & 2108 \\
\hline
\end{tabular}


Tabel 3 Intensitas Penyuluhan Pertanian Yang Dilakukan Penyuluh Pemerintah Selama Tahun 2017.

\begin{tabular}{cccccccc}
\hline Resp & Padi & Buah & Sayuran & Sapi & Kambing & Buras & Babi \\
\hline 1 & 3 & 2 & 2 & 1 & 1 & $\mathbf{2}$ & 1 \\
2 & 3 & 0 & 1 & 2 & 2 & 0 & 2 \\
3 & 2 & 0 & 2 & 2 & 2 & 0 & 1 \\
4 & 1 & 0 & 2 & 1 & 1 & 0 & 1 \\
5 & 3 & 2 & 1 & 1 & 1 & 0 & 2 \\
6 & 2 & 1 & 1 & 1 & 1 & 1 & 1 \\
7 & 3 & 1 & 1 & 2 & 2 & 1 & 1 \\
8 & 2 & 1 & 1 & 1 & 1 & 1 & 1 \\
9 & 1 & 1 & 0 & 2 & 2 & 1 & 2 \\
10 & 3 & 0 & 2 & 1 & 1 & 2 & 1 \\
11 & 3 & 2 & 1 & 1 & 1 & 2 & 1 \\
12 & 2 & 2 & 1 & 1 & 1 & 2 & 1 \\
13 & 1 & 1 & 2 & 1 & 1 & 1 & 2 \\
14 & 2 & 0 & 2 & 2 & 2 & 2 & 2 \\
15 & 3 & 0 & 1 & 1 & 1 & 0 & 1 \\
16 & 1 & 0 & 1 & 2 & 2 & 2 & 1 \\
17 & 2 & 2 & 1 & 1 & 1 & 2 & 2 \\
18 & 3 & 2 & 1 & 1 & 1 & 2 & 1 \\
19 & 1 & 1 & 2 & 1 & 1 & 1 & 1 \\
20 & 3 & 2 & 1 & 2 & 2 & 2 & 2 \\
21 & 2 & 2 & 1 & 1 & 1 & 2 & 1 \\
22 & 1 & 2 & 2 & 1 & 1 & 2 & 1 \\
\hline petani. Hal & ini & terlihat & dari kemampuan & di & daerah & yang bersangkutan & maupun \\
budidaya & ternak & sapi & potong & yang & pasar daerah terdekat. & & \\
tal & 2 & & & &
\end{tabular}

sebagian besar masih dilakukan sebagai tipe usaha sambilan dengan sistim pemeliharaan yang sangat sederhana dan terpencar-pencar. Para peternak dalam upayanya meningkatkan struktur usaha menjadi cabang usaha pokok masih terbentur pada permasalahan manajemen dan permodalan, dan untuk meningkatkan volume usaha, para peternak memerlukan tambahan biaya yang relatif besar. Disamping itu para peternak kurang mengetahui informasi pasar produk-produk peternakan, sehingga menyebabkan budidaya ternak sapi potong menjadi tidak berkembang. Akibatnya produksi ternak yang dihasilkan suatu daerah hanya dapat mensuplai pasar-pasar

\section{Deskripsi keadaan penyuluhan}

Tabel 3, menunjukan penyuluhan pertanian yang dilakukan oleh penyuluh pemerintah lebih banyak berkaitan dengan pengembangan usaha pertanian tanaman pangan dan hortikultura.

Untuk usaha peternakan lebih banyak dilakukan pada pengembangan usaha ayam kampung. Peternakan sapi potong lebih banyak berkaitan dengan materi tentang kesehatan ternak dan manajemen usaha. Tentang teknologi pakan sangat sedikit dilakukan penyuluh. 
Tabel 4. Intensitas Materi Penyuluhan Usaha Peternakan Sapi Potong Yang Didapat Petani

\begin{tabular}{|c|c|c|c|}
\hline $\begin{array}{c}\text { Responde } \\
\mathrm{n}\end{array}$ & Kesehatan Ternak & Manajemen & Teknologi Pakan \\
\hline 1 & 5 & 4 & 2 \\
\hline 2 & 4 & 4 & 2 \\
\hline 3 & 5 & 6 & 2 \\
\hline 4 & 6 & 6 & 1 \\
\hline 5 & 3 & 4 & 1 \\
\hline 6 & 4 & 4 & 2 \\
\hline 7 & 4 & 4 & 2 \\
\hline 8 & 5 & 6 & 2 \\
\hline 9 & 6 & 6 & 2 \\
\hline 10 & 3 & 4 & 1 \\
\hline 11 & 3 & 3 & 2 \\
\hline 12 & 3 & 3 & 1 \\
\hline 13 & 4 & 5 & 2 \\
\hline 14 & 4 & 4 & 2 \\
\hline 15 & 4 & 4 & 1 \\
\hline 16 & 5 & 5 & 2 \\
\hline 17 & 3 & 4 & 2 \\
\hline 18 & 4 & 4 & 1 \\
\hline 19 & 5 & 6 & 1 \\
\hline 20 & 6 & 6 & 1 \\
\hline 21 & 6 & 6 & 1 \\
\hline 22 & 4 & 5 & 2 \\
\hline Rata-rata & 4.36 & 4.68 & 1.4 \\
\hline \multicolumn{3}{|c|}{$\begin{array}{l}\text { Pada Table 4, penyuluhan pertanian } \\
\text { yang dilakukan khusus pada pengembangan } \\
\text { peternakan sapi potong masih belum } \\
\text { mengedepankan permasalahan pakan ternak } \\
\text { sebagai persoalan perkembangan populasi } \\
\text { sapi potong di kecamatan Totikum } \\
\text { Kabupaten Banggai Kepulauan. Materi } \\
\text { penyuluhan tentang teknologi pakan yang } \\
\text { didapat petani selama kegiatan usaha ternak } \\
\text { sapi rata-rata hanya } 1.40 \text { kali. Berbeda } \\
\text { dengan materi Kesehatan ternak dan } \\
\text { manajemen yaitu rata-rata } 4.36 \text { dan } 4.68 \\
\text { kali Sementara materi reproduksi hampir } \\
\text { sama dengan teknologi pakan, meskipun } \\
\text { angkanya lebih sedikit yaitu } 1.50 \% \text {. }\end{array}$} & $\begin{array}{l}\text { Deskripsi persepsi petani terhadap adobsi } \\
\text { inovasi teknologi pakan ternak sapi } \\
\text { potong } \\
\text { Hasil analisis pada Tabel } 5 \\
\text { menunjukkan bahwa persepsi "ragu-ragu" } \\
\text { petani terhadap proses adopsi inovasi } \\
\text { teknologi pakan ternak di Kecamatan } \\
\text { Totikum adalah persentasi paling tinggi, } \\
\text { meskipun bebeda sedikit dengan persepsi } \\
\text { "suka".hal ini mengartikan bahwa, peternak } \\
\text { sapi di Kecamatan Totikum masih } \\
\text { menyenangi usaha pemeliharaan ternak } \\
\text { ternak secara tradisional. Alasan petani } \\
\text { lebih praktis dibandingkan dengan } \\
\text { menyediakan pakan melalui proses olahan } \\
\text { teknologi. Namun bagi yg punya persepsi } \\
\text { "suka" karena atas pertimbangan untuk } \\
\text { meningkatkan kualitas daging ternak, }\end{array}$ \\
\hline
\end{tabular}


Tabel 5. Persepsi Petani Terhadap Proses Adopsi Inovasi

\begin{tabular}{lcc}
\hline Persepsi & Jumlah Responden & Persentase \\
\hline Suka & 7 orang & $32 \%$ \\
Ragu-ragu & 9 orang & $41 \%$ \\
Tidak Suka & 6 orang & $27 \%$ \\
\hline
\end{tabular}

Alasan petani bahwa pemberian pakan secara alami menyebabkan pertambahan berat badan ternak lambat (kurus). Sementara yang menyatakan "tidak suka" karena pertimbangan biaya yang diniliai lebih mahal jika dibanding pemberian pakan secara alami.

\section{KESIMPULAN}

Penyuluhan peternakan yang dilakukan di Kecamatan Totikum Kabupaten Banggai Kepulauan tidak berperan dalam proses adopsi inovasi teknologi pakan ternak sapi potong. Hal ini berdampak terhadap perkembangan pertumbuhan populasi ternak sapi potong menjadi lambat. Sehingga disarankan untuk meningkatkan intensitas penyuluhan dengan orientasi pada pengembangan adopsi inovasi teknologi pakan ternak sapi potong, serta menyediakan penyuluh peternakan yang berkompetensi dengan bidang keilmuan peternakan.

\section{DAFTAR PUSTAKA}

Adawiyah C.R, 2017. Urgensi komunikasi dalam kelompok kecil untuk mempercepat prose adopsi teknologi pertanian. Jurnal Forum Penelitian Agro Ekonomi, 35(1): 59-74.

Abdullah A dan H Ibrahim. 2014. Persepsi peternak terhadap kinerja penyuluh dalam pengembangan teknologi pengolahan jerami padi dan limbah ternak sapi potong. Jurnal Jitro 1(1):99-107.

Badan Pusat Statistik Kabupaten Banggai Kepulauan 2018.
Hamsa U, J Lainawa, G.D. Lenzun dan Z.M. Warow, 2021. Persepsi tokoh masyarakat dan peternak terhadap kinerja penyuluh dalam meningkatkan usaha peternakan sapi potong di Kecamatan Sangkub Kabupaten Bolaang Mongondow Utara. Zootek 41(1):44-52.

Laut M, A Winarso, N.A. Ndaong dan I Benu, 2018. Penerapan teknologi peternakan sebagai upaya peningkatan produksi ternak sapi potong di Desa Penfui Timur, Kecamatan Kupang Tengah, Kabupaten Kupang. Jurnal Pengabdian Masyarakat Peternakan. 3(1):21-31.

Mardikanto, Totok. 2010. Konsep-Konsep Pemberdayaan Masyarakat. Cetakan 1.Surakarta.UNS Press.

Moleong, L. J. 2017. Metodologi Penelitian Kualitatif. Edisi Revisi. Penerbit .PT. Remaja Rosdakarya. Bandung.

Narso, A Saleh, P.S. Asngari dan P Muljono, 2012. Strategi pengembangan peran penyuluh pertanian lapang di Provinsi Banten. Jurnal Penyuluhan 9(2):174-181.

Rusdiana, 2014. Konsep Inovasi Pendidikan. CV. Pustaka Setia. Bandung 2014.

Rusdiana S dan L Praharani, 2018. Pengembangan peternakan rakyat sapi potong: kebijakan swasembada daging sapi dan kelayakan usaha ternak. Forum Penelitian Agro Ekonomi 36(2):97-116.

Sari S, 2017. Faktor-Faktor Peternak Belum Melakukan Pengolahan Fermentasi Jerami Sebagai Pakan Ternak Sapi Potong Di Desa Mattirobulu 
Kecamatan Libureng Kabupaten Bone. Skripsi Fakultas Peternakan Universitas Hasanuddin Makassar.

Sondakh R.D, F.S. Oley, B.F.J. Sondakh, dan A.S. Sajow, 2019. Pengaruh penyuluh terhadap peternak sapi di Kecamatan Kowangkoan Barat. Zootec. 39 (2): 371-379.

Sugiyono. 2017. Metode Penelitian Kualitatif. Untuk Penelitian Yang Bersifat Eksploratif Enterpretatif, Interaktif dan Konstruktif. Penerbit, CV. Alvabeta. Bandung.

Sumardjo, Rizal, Syarief N.A, Kriswantriyono, dan Y.P Wulandari. 2015. Model Resolusi Konflik melalui Pendekatan Kedaulatan Pangan dan Pemberdayaan Masyarakat Rawan Konflik di Provinsi Papua. Bogor: Care LPPM IPB.

Sundari, A.H.A. Yusra dan Nurliza, 2015. Peran penyuluh pertanian terhadap peningkatan produksi usaha tani di Kabupaten Pontianak. Jurnal Social Economic of Agriculture 4(1):26-31.

Syatra U, S.N. Kasim dan A Asnawi, 2016. Pengaruh pengetahuan, motivasi, dan biaya inseminasi buatan terhadap adopsi teknologi IB peternak sapi potong di Desa Waji Kecamatan Tellu Siattinge Kabupaten Bone. Jurnal JIIP, 3(2):71-76.

Yafi G.H, 2017. Persepsi Dan keputusan Peteani Terhadap Inovasi Teknologi Persemaian Tertutup. Skripsi Program Studi Agribisnis Fakultas Pertanian Universitas Brawijaya Malang. 